\title{
Parametric Study of Torsional Damper on Crankshaft Life Assessment of an IC Engine
}

\author{
H. Karimaei ${ }^{*}$, H. Chamani ${ }^{2}$ \\ 1. Aerospace Research Institute, Ministry of Science, Research and Technology, Tehran, Iran \\ 2. Fatigue and Fracture lab, Center of Excellence in Experimental Solid Mechanic and Dynamics, School of \\ Mechanical Engineering, Iran University of Science and Technology, Tehran, Iran
}

\begin{abstract}
Torsional vibration (TV) is one of the major issues and very important calculation for the safe running of internal combustion engines, specifically crankshaft. The properties of parts connected to the crankshaft have significant effect on vibration of the system as well as the crankshaft life. Initial selection of this part is usually specified based on engine designer experience and also the torsional vibration calculation of the crank train. In this paper, the focus is to find optimum tuned mass to connect to the crankshaft from the damper side using CAE tools. It is a mounting disk at the free end of the crankshaft named tuned mass. Therefore, the effect of tuned mass inertia on design criteria, especially crankshaft life, was investigated. The results show high sensitivity of high cycle fatigue safety factor of crankshaft to tuned mass. Therefore, adding a suitable tuned mass to the system can increase the crankshaft life, when needed. The results were presented in the paper in detail.
\end{abstract}

Keywords: Classical Torsional vibration, Cranktrain, Tuned mass, High cycle fatigue, Crankshaft life.

\section{Introduction}

Torsional Vibration (TV) is one of the major issues and important calculation inthe safe running of heavy-duty diesel engines, specifically crankshaft. Torsional vibration analysis is a common simulation task in the design process of cranktrain systems in internal combustion engines [1]. The Holzer method has been successfully used for the calculation of torsional vibration for many years ([2], [2] and [3]). There are several codes developed for solving the torsional vibration problem which are validated with experimental results. The results of three computational codes which had been developed for solving the torsional vibration problem, including Holzer-forced vibration method, TORVAP and TSC have been compared by Chen and Chang [4]. Also a simulation method for torsional vibration was represented by Hafner and Maass[3], and a torsional vibration solution by Matrix method was presented by Larmi [6]. In these methods, the effects of variable inertia of ICEs were ignored. However, it is shown that the torsional vibration of reciprocating engines cannot be accurately modelled without considering variable inertias.

Some solution methods for torsional vibration problem based on the Multi-Body Dynamic (MBD)

\footnotetext{
* Corresponding Author Email: karimaei@ari.ac.ir
}

were presented by Boysal and Rahnejat [6]; Ma and Perkins [7]; in which the exact equations of the motion based on the multi-body dynamic, including the variable inertia effect has been considered. Aiming at monitoring large diesel engines was done by Desbazeille et al [9] by analysing the crankshaft angular speed variations. It is focused on a powerful 20-cylinder diesel engine with crankshaft natural frequencies within the operating speed range. Mechanical and combustion parameters of these models were optimised with the help of measurement data.

By Han et al [10], the root cause analysis of the high torsional vibration which occurred in the actual ship through a parametric study performed using numerical analysis were described. Parameters that can increase the torsional vibration of the propulsion shaft were selected. To find the cause of the malfunctions, a simulation model coupling the speed control system with the torsional vibration of the deformable shafting was proposed and investigated by Guo et al [11]. In the coupling model, the shafting was simplified to be a deformable one. The results of instantaneous rotation speed from this proposed model agreed with the test results very well.In the work of Karimaei et al [12] the focus was to find the optimum and reliable operating points for the elements in cranktrain using computer- 
aided engineering (CAE) tools. The results show high sensitivity of crankshaft safety factor to parameters like tuned mass inertia and damper. Based on the study of Jee et al [13]it is very difficult to control the torsional vibration of the shaft system by adopting a damper, for ships equipped with fuel-efficient ultra-long-stroke engines, even though previously, torsional vibration could be controlled adequately by applying tuning and turning wheels on the engine. In theirstudy, the vibration characteristics of an ultra-long-stroke engine using the de-rating technology are reviewed. Also, dynamic characteristics of a viscous-spring damper used to control the torsional vibration of its shaft system are also examined. It is proposed that the appropriate measures to control the torsional vibration in the propulsion shafting system should include adjusting the design parameters of its damper instead of using the optimum damper designed from theory in order to prevent fatigue fracture of shafts.

About the torsional vibration calculation and investigation of torsional system, many studies have been done up to now, but the lack of a complete study of the parameters of torsional damper affecting torsional vibrations was completely felt. Therefore, the present study was done. The focus in the work of Karimaei [14] was to find optimum tuned mass to connect to the crankshaft from the damper side using CAE tools. Therefore, the effect of tuned mass inertia on design criteriawas investigated. The results show sensitivity of high cycle fatigue safety factor of crankshaft to tuned mass.

In the present paper, two different software have been used to analyse the torsional vibration system. The first one was carried out using $\mathrm{ADAMS}^{\circledR} /$ Engine commercial software, and the next one was carried out by $\mathrm{AVL}^{\circledR} /$ Designer. In $\mathrm{ADAMS}^{\circledR} /$ Engine, the crankshaft is considered as the torsional-flexible part and the solution is carried out based on the Multi-Body Dynamic [15]. The procedure of torsional vibration analysis in $\mathrm{AVL}^{\circledR} /$ Designer software is based on the Holzer-Forced Vibration method [16]. Finally, the results of the both analyses are presented and compared in the following. Optimising the characteristics of torsional vibration elements such as the damper is a key issue in designing a torsional vibration system. In a TV system, there are many elements, but not all of their properties could be changed for different applications such as crankshaft stiffness or the size of the elements. The focus in the present paper is on the effect of the torsional damper characteristics on the whole cranktrain system and, therefore, a detailed torsional vibration solution method is implemented. The effects of torsional damper characteristics on the crankshaft life such as the crankshaft fatigue safety factors (SF) were studied here that can be used for selection of the optimum damper.

\section{Torsional Vibration Calculation}

Torsional vibration calculation analysis is performed based on the formulation of a torsional vibration model. The engine shafting system is divided in several rigid bodies (Fig. 1), i.e. some masses. The torsional springs connect these masses to each other. The components in this engine cranktrain system are as shown in Fig. 1. The engine crankshaft is divided to 7 masses (mass numbers 3 to 9). Mass numbers 4 to 9 corresponds to six crankshaft throws and mass number 3 corresponds to crankshaft end shaft and flange and tuned mass including the gears and camshaft inertia. Here a new developed turbocharged inline six-cylinder diesel engine has been studied. The rated power of engine is $700 \mathrm{~kW}$ at $1800 \mathrm{rpm}$. In this paper the torsional system of this engine in the steady power generation application is studied.

The important characteristics of a torsional vibration system including inertia, stiffness and damping coefficient are described as follows:

\section{Inertia}

3D solid model of the crankshaft was drawn using Pro/Engineer. The inertias of the system can be determined by CAD software. The inertia of a single crank throw is calculated by cutting it from the crankshaft model. Engines usually have a gear train for power transmission to other devices such as water pump, oil pump and camshaft. The inertia of this system is considered in an equivalent model and added to the inertia of number 3 in Fig. 1. Connecting rods also were considered as two divided mass in AVL ${ }^{\circledR}$ and in ADAMS ${ }^{\circledR}$ which is simulated by the centre of gravity location, mass and inertia tensor.

\section{Stiffness}

The torsional stiffness of all sections of the crankshaft model can be calculated using the finite element method, such that a constant torque is applied at the one side of the part while the other side is clamped. Then the twist angle is obtained. The relation between the torque and the calculated twist angle is the torsional stiffness considered in the equivalent model. Therefore, the torsional stiffness can be calculated as follows:

$$
K_{t}=\frac{T}{\theta}
$$

More details for such a calculation have been done by Milasinovic et al. [17].

The type of damper considered here is Geislinger damper. The Geislinger steel spring damper consists of a primary (fixed) part and a secondary (seismic) part, which are couplled by steel spring elements (Fig. 2.).

\section{Damping coefficient}

The relative damping coefficient between two engine crankshaft throws, $\mathrm{Cr}$, can be obtained from the loss 
angle property. The loss factor is 0.06 for small engines up to 0.28 for big engines and could be expressed by the

$$
C r(i)=\frac{k t(\mathrm{i}) \cdot \chi}{i \cdot n}
$$

following equation[3]:

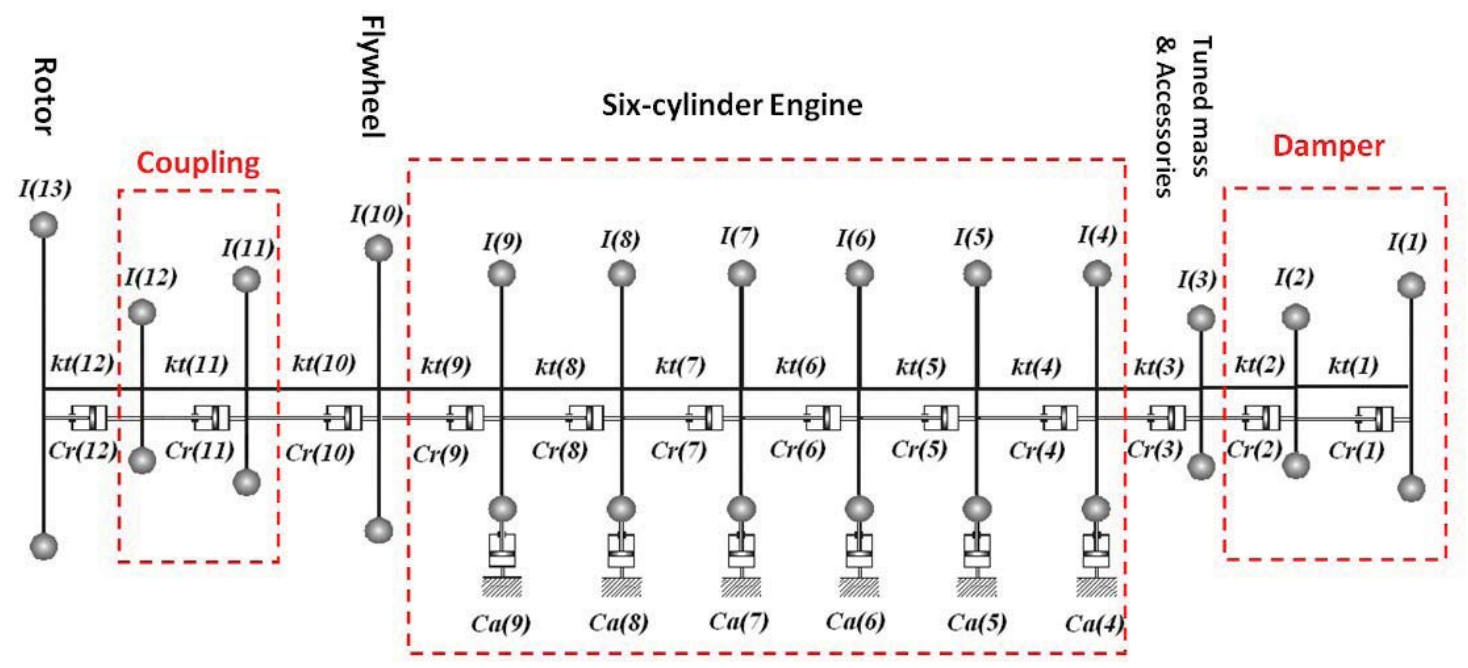

Figure 1. Torsional vibration model

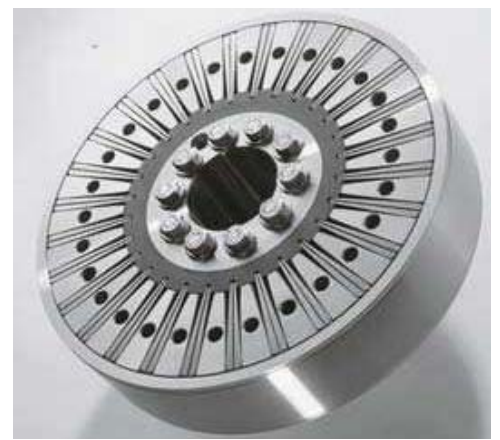

Figure 2. Geislinger ${ }^{\mathbb{B}}$ damper [18]

Also the external damping coefficient, $\mathrm{Ca}$, can be calculated by the following equation [3]:

$$
C a(i)=\frac{\text { fmep. } V_{h}}{4 \cdot \pi \cdot n \cdot i \cdot n_{c}}
$$

The damping of the damper is produced by the pressurised oil pumped through specially designed hydrodynamic gaps. The amount of the damping coefficient is supplied by Geislinger, and also can be measured on the test bed by a special method as discussed by Philipp [19] by the following formula:
$d_{e}=\frac{\left|T_{c} \varphi_{s}-T_{s} \varphi_{c}\right|}{\left(\varphi_{c}^{2}+\varphi_{s}^{2}\right) \omega}$

The damping factors in the torsional system are gotten from their suppliers.

\section{Excitation and boundary condition}

In the torsional vibration system, the excitation per cylinder is usually loaded by a tangential pressure and inertia components as described in B.I.C.E.R.A [2]. Here, gas forces at different speeds, as shown in Fig. 3, were used for excitation in both software applied on the pistons. The gas pressures at different engine speeds were measured using high temperature piezoelectric pressure sensors for three cylinders. The engine operation speed is in the range of $600 \mathrm{rpm}$ (Idle) to 1800 rpm (maximum rated speed). Considering 15\% overspeed for the engine, the engine speed may increase up to $2070 \mathrm{rpm}$. Inertia loads are also calculated based on the model mass and inertia properties by the software.

As mentioned before, the first model was created based on the Multi-Body Dynamic in ADAMS ${ }^{\circledR}$. The boundary conditions consisting gas forces and engine mountings were applied to the model. In addition, a constant rotation speed was applied to the driven machinery. The coupling and the rotor were attached to the flywheel end of the crankshaft in $\mathrm{ADAMS}^{\circledR}$. 


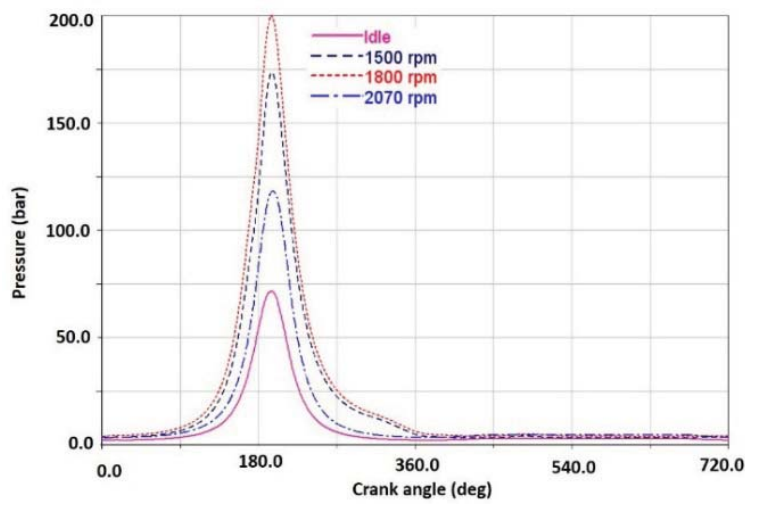

Figure 3. Gas pressure in different speed

The other model was created in AVL Excite ${ }^{\circledR}$ which is very similar to $\mathrm{ADAMS}^{\circledR}$ model, but the method of solution is based on the Extended (include exciting) Holzer Method as mentioned before, (AVL Theory Manual). The natural frequency and mode shapes of a multi-mass lumped parameter system can be determined by this iteration method as devised by Holzer. It's applicable to forced, free, damped, undamped and semi-definite systems as well. A typical multi-rotor system can be considered as shown in Fig.4

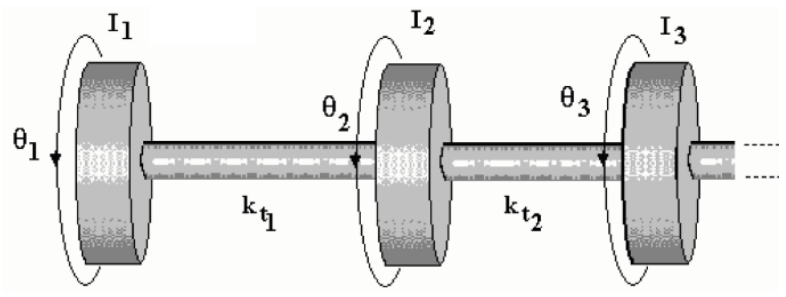

Figure 4. Multiple inertia system

For any number of discs this may be generalized as $\sum I \omega^{2} \theta=0$. Holzer's method of solution proposes that be assumed any value of $\omega$ and made $\theta_{1}=1$ and calculated all the other deflections. Since $\sum I \omega^{2} \theta=0$ must be satisfied, then the last $\mathrm{T}$ must be zero when the oscillation is free. The problem is to find the values of $\omega$ that make this so and these are the natural frequencies of the system.If a computer program is used, it is relatively simple to evaluate the displacements and the torqued for all valued of $\omega$.

\section{Problem}

The first step is initial selection of damper characteristics which usually is done based on the engine manufacturer experience. In the following, the design variables, purposes and constraints for the problem are discussed.

\section{Design variables of damper}

The damper utilised in this study allows a precise tuning of torsional stiffness $C$, damping $\mathrm{d}$, and moment of inertia $(I)$ in order to implement the requirements of the given torsional system. Therefore, these parameters are considered as the design variables in the system [19].

Selection of the damper inertial mass and stiffness is the initial stage, and therefore, it is important to generally review the effect of attaching a damper. The dynamic magnifier versus the frequency ratio for the original system (without a damper) is shown in Fig. 5, by a chain-dotted curve. Fitting of a damper practically adds another mass and elasticity to the system and, therefore, it changes the system natural frequency. Adding the damper mass clamped to its hub means that the damper has infinite damping; the slightly lower frequency than the original natural frequency is obtained. For a damper with no damping constant, two frequencies are found; one higher and the other lower than the previous frequency. According to the inertia and stiffness which are chosen for the damper, three natural frequencies can be calculated (for infinite and zero damping); for example, for the $6^{\text {th }}$ dominant order in a six-cylinder engine, as shown in Fig. 5. With no damping, the amplitudes for the damper mass and crankshaft will be infinite as shown by the two outer dotted curves. However, this state never occurs because the damper operates in a real condition.

It is found that the actual dynamic magnifier as per any value of damping coefficient is in the range of 0 to $\infty$; these curves pass through the characteristic frequency points (circlled points). Infinite damping represents a case of locked absorber condition. The relative dynamic magnifier at these points depends only on the damper mass and the stiffness and also the dampened vibrations pass through these two fixed points when damping is considered for the damper. It should be attempted to arrange the fixed points at low and identical amplitudes to have a good tuning. If the torsional amplitudes of the fixed points are too high, the damper size will be too small.If the fixed points are not at the same level amplitude, the calculation should be repeated by changing the damper stiffness until these fixed points get to the same level amplitude.

The next step is the selection of the damping coefficient based on the initially selected stiffness and inertia values. By using of the non-dimensional damping factor $C / C_{c}$, a quick checking of the damping magnitude, independent of the damper size, can be done. Different non-dimensional damping factor can be considered. An optimum damping value will be achieved with considering that the final curve of the damped vibration should be flat over a wide speed range without any distinct resonance.By this way, it is possible to achieve some properties for the damper but an important point is that the engine has many dominant or critical orders. Fig. 6 shows the dominant orders of torsional system of 
this engine. As illustrated, there are many dominant orders that should be considered to find the optimum values for the damper. The important orders are the harmonic torque components, which cumulatively act to intensify the torsional twist of the shaft in its normal mode of vibration. It should be mentioned that the damper selection by prescribed method is very useful to find the optimum damper. But the point to note is that because of the nonlinear nature of the torsional system and existing many dominant orders, finding the best value is not completely achievable and, therefore, the full torsional vibration analysis is inevitable. That way the synthesis of all order amplitudes and the exact result of objective values can be considered to find the optimum value for the damper characteristics.

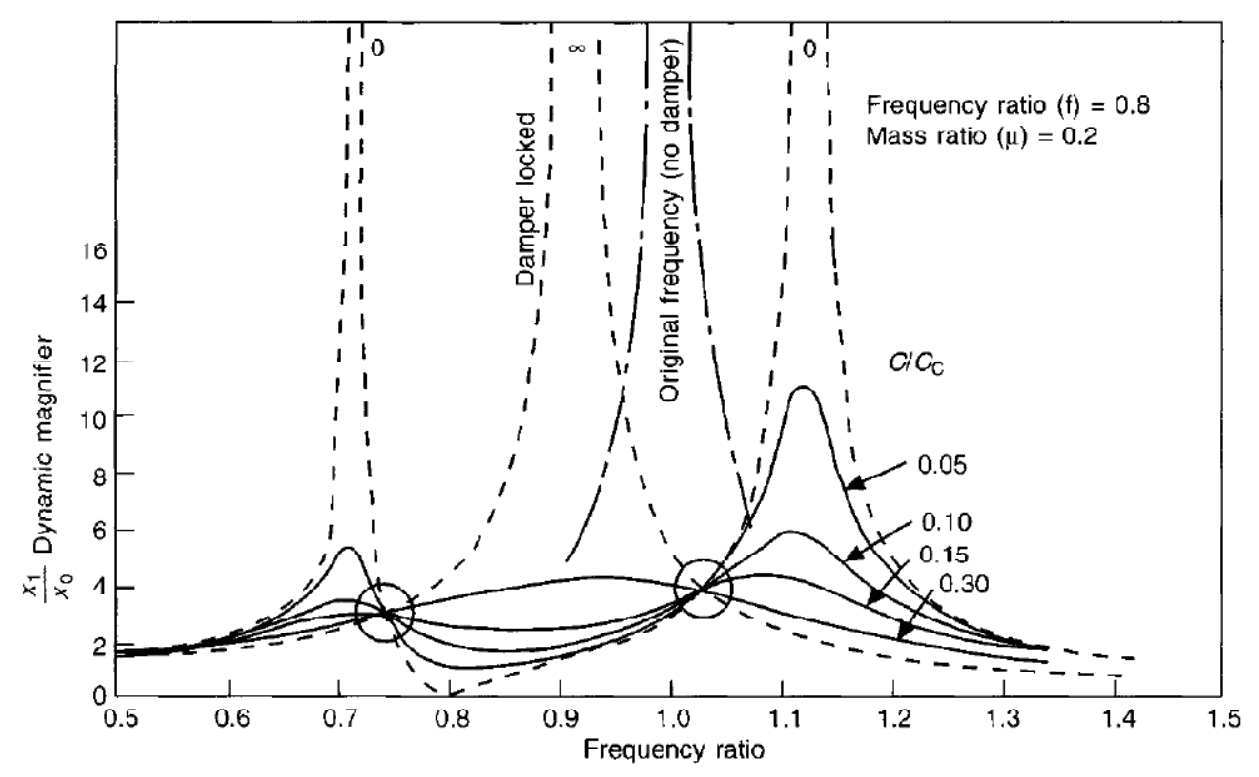

Figure 5. Dynamic magnifier versus forced frequency ratio for tuned damper and various damping ratios (Beards [20])

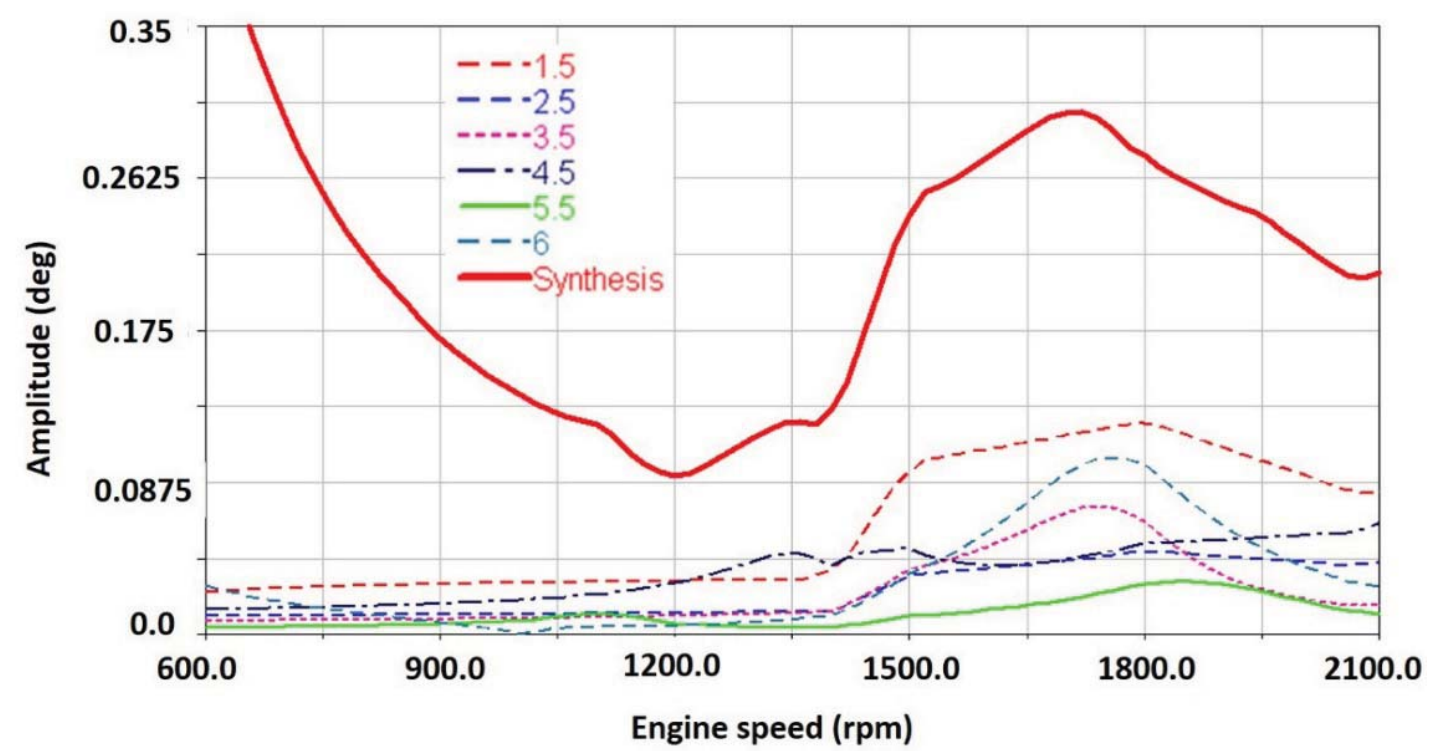

Figure 6. Dominant orders of torsional system 
Table 1. Parameters, purposes and constraints for the problem

\begin{tabular}{lll}
\hline Design variables & Purposes & Constraints \\
\hline Damper inertia & Crankshaft torsional torque amplitude & Damper elastic torque \\
Damper stiffness & Consequently: & Damper damping torque \\
Damper damping & Fatigue safety factor in crank pin fillet & \\
& Fatigue safety factor in journal pin fillet & \\
\hline
\end{tabular}

\section{Purposes}

The first important factor which should be considered in an engine torsional system design is the torsional torques applied to the crankshaft which directly affects the crankshaft safety factor. This safety factor is defined based on crankshaft strength assessment methods which have been standardised by classification societies through IACS (International Association of Classification societies [21]) namely UR-M53.

The typical areas of interest for a crankshaft are the journal pin fillet, crank pin fillet and oil holes. These are the main three regions where stress concentration is relatively high because the cross-section changes at these points. In the current case, the crank pin fillet and oil holes are critical sections. Using UR-M53 classification rule, the levels of the fatigue safety factor in the crank pin fillet, journal pin fillet and oil holes are derived.

\section{Constraints}

There are also some other factors which should be investigated as the constraints of this problem. These are mostly determined by the manufacturers, such as maximum permissible torque and etc. that should be satisfied.

\section{Results}

As described before, the selection process of optimum damper is started with the selection of the initial values for the torsional system properties. The parameters listed in Table 1 are studied to optimise the torsional system properties. All parameters are changed in the range of $\pm 25 \%$ around the initial values specified in the parenthesises, as shown in Table 2.

Table 2. Variation interval (initial values are specified in parenthesises)

\begin{tabular}{cccc}
\hline $\begin{array}{c}\text { Trial } \\
\text { number }\end{array}$ & $\begin{array}{c}\text { Damper } \\
\text { stiffness } \\
(\mathrm{MNm} / \mathrm{rad})\end{array}$ & $\begin{array}{c}\text { Damper } \\
\text { inertia-outer and inner } \\
\text { ring } \\
(\mathrm{kgm} 2)\end{array}$ & $\begin{array}{c}\text { Damper } \\
\text { damping } \\
(\mathrm{Nms} / \mathrm{rad})\end{array}$ \\
\hline $\mathbf{1}$ & 0.332 & $0.739-0.0495$ & 112.500 \\
$\mathbf{2}$ & 0.349 & $0.775-0.0519$ & 121.875 \\
$\mathbf{3}$ & 0.376 & $.0811-0.0543$ & 131.250 \\
$\mathbf{4}$ & 0.403 & $0.847-0.0567$ & 140.625 \\
$\mathbf{5}$ & $(0.43)$ & $(0.0883-0.0591)$ & $(150.000)$ \\
$\mathbf{6}$ & 0.457 & $0.0919-0.0615$ & 159.375 \\
$\mathbf{7}$ & 0.484 & $0.955-.0639$ & 168.750 \\
$\mathbf{8}$ & 0.511 & $0.991-0.0663$ & 178.125 \\
$\mathbf{9}$ & 0.536 & $1.0026-0.0687$ & 187.500 \\
\hline
\end{tabular}

The effects of inertia, stiffness constant, and damping constant of damper are shown in Fig.7 to Fig.9. Damper stiffness has considerable effect on the nominal alternating torque and consequently on the crankshaft safety factors. Damper inertia has small effect on the nominal alternating torques. As illustrated in Fig.9, it could be deduced that damper damping constant has important effect on the nominal alternating and consequently on the fatigue safety factors.

The effects of different torsional system properties were presented in Table 3. It should be mentioned that however the two simulation packages (ADAMS $®$ and AVL () have two different methods, but their results have close agreement. This shows the acceptability of the results of each software package for doing an optimisation process. The main important purpose in this problem is the crankshaft fatigue life which is mainly depends on the nominal alternating torque. Therefore, the influential parameters are damper damping constant, stiffness and inertia. These parameters are considered as the variables used in problem, therefore, this experiment is limited to study the effect of three mentioned factors.

This experiment involves the study of the effects of three factors as mentioned before. The damping effect, as described in this section, is completely depended on the damper inertia and stiffness and these two parameters have priority in selection. Therefore, in the first step the optimisation is carried out with these two variables, i.e. damper inertia and stiffness. 




Figure 7. Effect of damper stiffness on nominal alternating torque in critical section of crankshaft

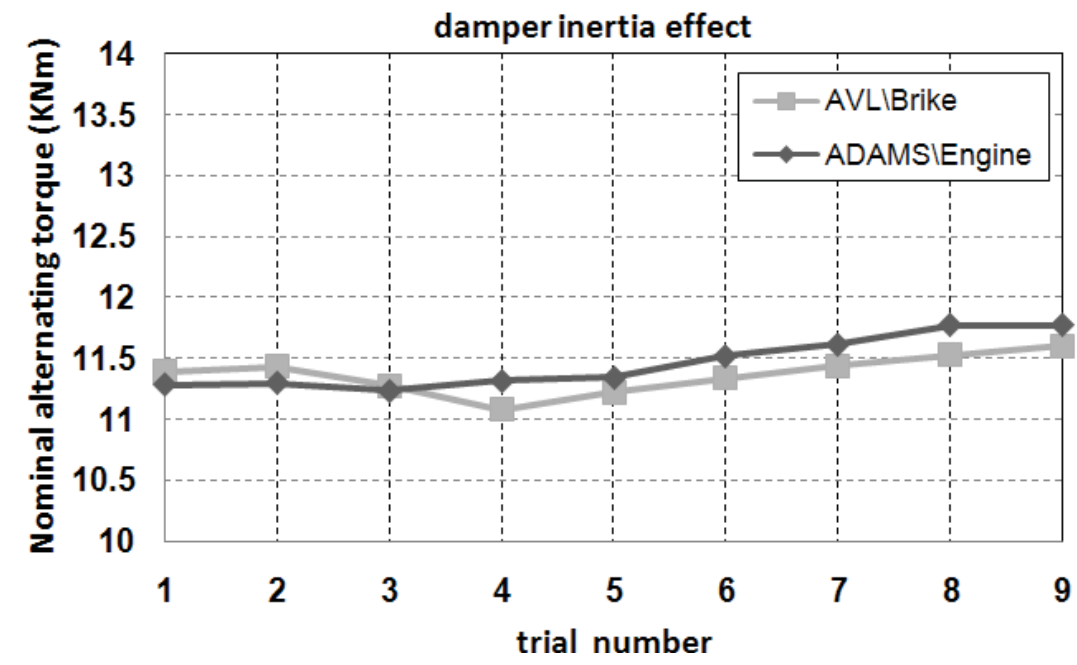

Figure 8. Effect of damper inertia on nominal alternating torque

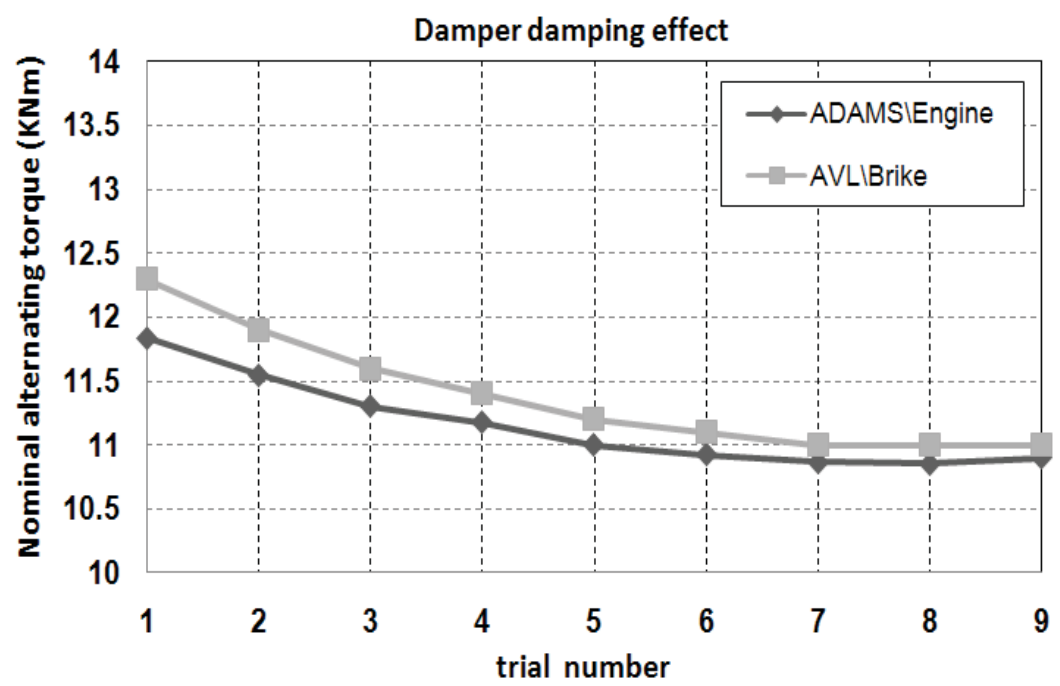

Figure 9. Effect of damper damping on nominal alternating torque in critical section of crankshaft 


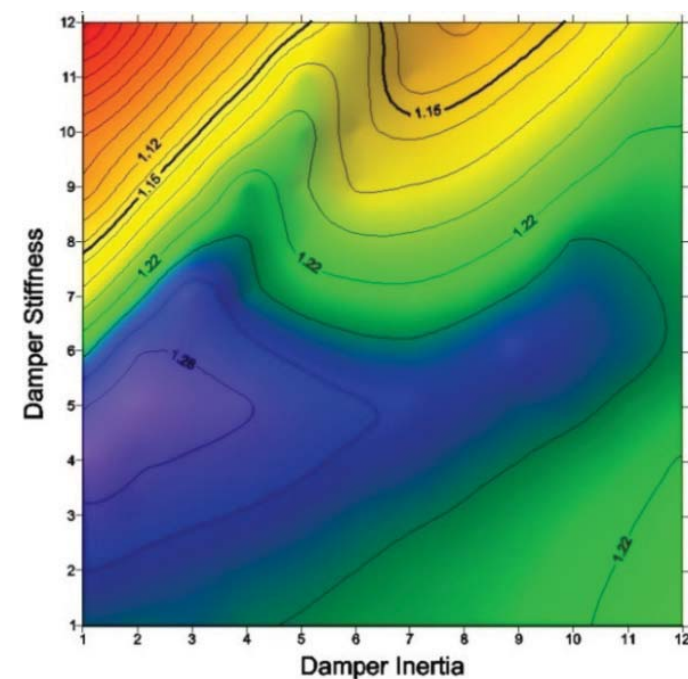

a)

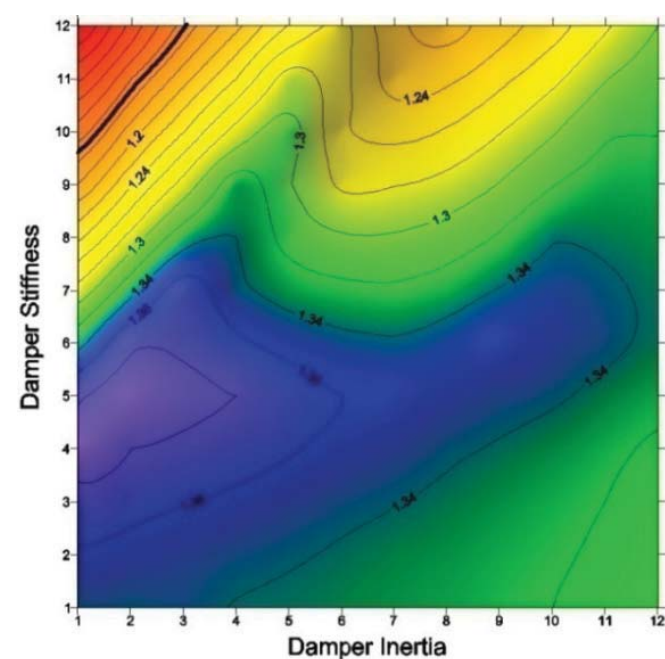

b)

Figure 10. a) Crankshaft crankpin oil hole safety factor based on URM53, b) Crankshaft crankpin fillet safety factor based on URM53

Table 3. effect of parameters

\begin{tabular}{ccccc}
\hline & $\begin{array}{c}\text { Nominal } \\
\text { alternating } \\
\text { torque } \\
(\mathrm{KNm})\end{array}$ & $\begin{array}{c}\text { Crank } \\
\text { pin } \\
\text { fillet } \\
\mathrm{SF}\end{array}$ & $\begin{array}{c}\text { Crank } \\
\text { pin } \\
\text { oil } \\
\text { hole }\end{array}$ & OVERALL \\
\hline Damper & $\mathrm{H}^{* *}$ & $\mathrm{H}$ & $\mathrm{H}$ & $\mathrm{H}$ \\
Damper & $\mathrm{H}$ & $\mathrm{H}$ & $\mathrm{H}$ & $\mathrm{H}$ \\
Damper inertia & $\mathrm{M}^{*}$ & $\mathrm{M}$ & $\mathrm{M}$ & $\mathrm{M}$ \\
\hline
\end{tabular}

Note: *Medium, ** High

The optimum parameters are obtained for the optimum objective values, as shown in Fig.10. a and 10. b. The horizontal and vertical axes are related to the damper inertia and stiffness values, respectively. The optimum value for the damper inertia and stiffnesscan be obtained from the figures. It is clear that a lighter damper increases the crankshaft safety. The next step is to check the effect of different values of damper damping constant with considering new damper inertia and stiffness values and investigate the purposes due to changingthis parameter.

As shown in Fig.11, the current value for damper damping constant (trial number 5) is appropriate as purpose and no more iteration is required. The results depict that the nominal alternating torque has lower variation by changing the damper damping constant in the interval of $\pm 25 \%$ with new damper stiffness and inertia. This is a good characteristic in the torsional system because there are some difficulties to calculate the damping constant and also that the damper loses its damping property during its life.



Figure 11. Effect of damper damping on nominal alternating torque in critical section of crankshaft

\section{Conclusion}

To study the effect of different characteristics of TV damper of a heavy-duty inline diesel engine on TV system design criteria, two useful commercial software were employed. The first simulation was carried out using $\mathrm{ADAMS}^{\circledR} /$ Engine, and the next one was carried out by $\mathrm{AVL}^{\circledR} /$ Designer software.

In fact, the two different methods, implemented by the two mentioned different software packages, have been used to study the torsional vibration system. However, these are different in method, but have close agreement in the results which confirms the correctness of the simulation and shows the reliability of the results. It was already described about the importance of selecting the initial characteristic values for the damper.

The results showed that torsional damper properties have a great effect on the torsional system, so that its optimal selection can greatly improve the crankshaft life. Lighter damper increases the crankshaft safety. The 
optimisation causes an improvement in the crankshaft life and it also leads to the use of a lighter damper and subsequentlya cheaper damper for the engine.Optimisation parameters, discussed in this paper, including damper stiffness, damper inertia and damper damping, all of them, are practical and selectable. There is a full authority to select a damper and maneuver on choosing a damper to adapt with the requirement for passing the standards of crankshaft life. But about crankshaft properties (like stiffness and inertia of throws, and damping of them), the maneuverability is low, because the crankshaft must be able to withstand the loads and at the same time be light enough. Based on above description, in terms of operational, designers are free to choose a suitable damper.

\section{Funding}

This research received no specific grant from any funding agency in the public, commercial, or not-forprofit sectors.

\section{Nomenclature}

\section{Latin letters}

$\mathrm{Cr} \quad$ Relative damping coefficients between two engine crankshaft throws $[\mathrm{Ns} / \mathrm{m}]$

$\mathrm{Ca}$ External damping coefficients $[\mathrm{Ns} / \mathrm{m}]$

c Primary part of damper

$\mathrm{d}_{\mathrm{e}} \quad$ Damper damping [Nms/rad]

i Combustion cycles per revolution

I Inertia, Inertia of crankshaft throw [kg.m2]

$\mathrm{K}_{\mathrm{t}} \quad$ Stiffness, Stiffness of crankshaft throw [N/m]

$\mathrm{n} \quad$ Engine speed $[\mathrm{rpm}]$

s Secondary part of damper

$\mathrm{T} \quad$ Vibratory torque $\backslash$ Torque $[\mathrm{Nm}]$

$\mathrm{V}_{\mathrm{h}} \quad$ Cylinder volume [m3]

\section{Greek letters}

$\begin{array}{ll}\chi & \text { Loss factor } \\ \theta & \text { Twist angle [Rad] } \\ \omega & \text { Phase velocity of vibration, } \mathrm{rad} / \mathrm{s} \\ \varphi & \text { Vibratory angle propeller, } \mathrm{rad}\end{array}$

\section{Abbreviations}

fmep Friction mean effective pressure [bar]

$\mathrm{nc}$

Number of crank throws

\section{References}

[1] Mendes, A. S., Meirelles, P. S., and Zampieri, D. E., "Analysis of torsional vibration in internal combustion engines: modelling and experimental validation," Proceedings of the Institution of Mechanical Engineers, Part K: Journal of Multi-body Dynamics, 222(2): pp. 155-178, 2008.
[2] Nestorides, E. J., ed. A handbook on torsional vibration. Cambridge University Press, 1958.

[3] Wilson, WK., Practical solution of torsional vibration problems: with examples from marine, electrical, aeronautical, and automobile engineering practice., Chapman \& Hall; Vol. 2, 1956.

[4] Hafner, KE. and Maass, H., Theorie der Triebwerksschwingungen der Brennkraft maschine, WienNew York; Vol. 3, 1984.

[5] Chen, S.K., and Chang, T., "Crankshaft torsional and damping simulation - an update and correlation with test results," SAE transactions, pp. 964-985, 1986.

[6] Larmi, M. "Torsional vibration calculation and engine damping," Proceedings of international congress on combustion engines (CIMAC), pp. 96-105, 1988.

[7] Boysal, A., and Rahnejat, H., "Torsional vibration analysis of a multi-body single cylinder internal combustion engine model," Applied Mathematical Modelling, 21(8): pp. 481493, 1997.

[8] Ma, ZD. and Perkins, NC., "An efficient multibody dynamics model for internal combustion engine systems." Multibody system dynamics, 10(4): pp. 363-391, 2003.

[9] Desbazeille, M., Randall, RB., Guillet, F., El Badaoui, M. and Hoisnard, C. "Model-based diagnosis of large diesel engines based on angular speed variations of the crankshaft," Mechanical Systems and Signal Processing, 24(5): pp. 1529-1541, 2010.

[10] Han, HS., Lee, KH. and Park, SH. "Parametric study to identify the cause of high torsional vibration of the propulsion shaft in the ship," Engineering Failure Analysis, 59(1), pp. 334-346, 2016.

[11] Guo, Y., Li, W., Yu, S., Han, X., Yuan, Y., Wang, Z. and Ma, X., "Diesel engine torsional vibration control coupling with speed control system," Mechanical Systems and Signal Processing, 94 (1): pp. 1-13, 2017.

[12]Karimaei,H., Mehrgou, M., and Chamani, HR. "Optimisation of torsional vibration system for a heavyduty inline six-cylinder diesel engine, " Proceedings of the Institution of Mechanical Engineers, Part K: Journal of Multi-body Dynamics, 233(1): pp. 642-56, 2019.

[13]Jee, J., Kim, C., Kim, Y., "Design Improvement of a Viscous-Spring Damper for Controlling Torsional Vibration in a Propulsion Shafting System with an Engine Acceleration Problem," Journal of Marine Science and Engineering, 8(6): pp. 428-438, 2020.

[14]Karimaei,H., "Sensitive Analysis of Tuned Mass on High Cycle Fatigue Safety Factor of Crankshaft," International Journal of Reliability, Risk and Safety: Theory and Application, 2020 Nov; Articles in Press.

[15] MSC ADAMS. Documentation and help. Using Adams/Engine. 2005.

[16] AVL LIST GmbH. AVL Excite Designer, Theory Manual Version 7.0.3. October 2007.

[17] Milasinovic, A., Filipovic, I., and Hribernik, A. "Contribution to the definition of the torsional stiffness of 
the crankshaft of a diesel engine used in heavy-duty vehicles." Proceedings of the Institution of Mechanical Engineers, Part D: Journal of Automobile Engineering, 223(7): pp. 921-930, 2009.

[18] Geislinger Damper Catalogue. Geislinger GmbH. 5300 Hallwang/Austria. 2016.

[19] Philipp, T., "Parametric Identification of Torsional Vibration by Modern Measurement and Calculation
Methods, " CIMAC Congress, Vienna, Paper. No. 130, pp. 2-13, 2007.

[20] Beards, CF., "Introduction to finite element vibration analysis, " Aeronaut J, 103(1): pp. 486-490,1999.

[21] IACS UR M53, International Association of Classification Societies (IACS) Unified Rules UR-M53 for the calculation of Crankshaft Design Strength Assessment for I.C. Engines. 1986 (Rev.1, Dec 2004). 